\section{EDUCATION AND TRAINING OF SPECTROSCOPISTS}

$\mathrm{T}$

HE great interest, long overdue, which is now being demonstrated by scientists in their own education, was reflected at a well-supported combined meeting, on February 15, of the Industrial Spectroscopy and the Education Groups of the Institute of Physics on the "Education and Training of Spectroscopists". Speakers were drawn from various branches of spectroscopy and were representative of the universities, technical colleges, research institutions and industry.

In his opening remarks Dr. A. C. G. Menzies (chairman of the Industrial Spectroscopy Group) referred to his own experiences both as university teacher and industrialist, but based his remarks mainly on the recent Stationery Office publication on "Scientific and Engineering Man-Power in Great Britain". He believes that the shortage of scientific man-power is still under-estimated; insufficient weight has been given to the increasing modernization of many of the smaller industrial concerns, which is causing the demand for scientists to increase at a faster rate. Even so, he considered that maintenance of high standards is just as necessary as the production of greater numbers.

Dr. H. Powell (B-P Research Station) deplored the general attitude, apparent in applicants for posts, of neglect and even disparagement of analytical work in academic circles. The requirements of the two main branches of spectroscopy are somewhat different. Whereas in molecular spectroscopy the technique is relatively simple, although interpretation of results requires a man of good graduate status, emission technique is difficult and requires welltrained and experienced staff to carry out experimental work in addition to graduate supervisory staff. He considered that more spectroscopy could be included in university degree courses, and made suggestions as to how this could be achieved with the minimum expenditure of time and money. Suitable instruments could be constructed and tested as part of an honours physics course and then be transferred to the chemistry department for application in, for example, the identification of molecular structure and quantitative spectrochemical analysis. Also, technical colleges could organize more part-time courses on spectroscopy for non-graduate staff. Consideration might also be given by universities and colleges to inviting experts from industry to give special lectures to final-year students. Dr. Powell then discussed the selection and training of staff in his own establishment and emphasized the value of commissioning reports on new equipment in the practical training of new entrants.

Dr. G. H. Beaven (National Institute for Medical Research) considered that the great value of applied molecular spectroscopy in the solution of complex analytical problems and its largely empirical use in diagnosis of molecular structure should not be allowed to obscure the fact that these applications are based on a highly-developed fundamental theory. The prime function of university training in mole. cular spectroscopy must therefore be to provide students with authoritative instruction in the fundamentals rather than applications of specific instruments. Frequent suggestions that university courses should be broadened, particularly in cultural and technological content, have been made and extreme examples can be found in the discussion at the conference held by the Royal Institute of Chem. istry on "The Training and Education of Chemists" (J. Roy. Inst. Chem., 80, 493; 1956). Even after tactful editing, the report on the discussion (Nature, $179,78 ; 1957)$ makes it evident that some industrialists would prefer university science teaching to be concentrated on technology rather than on fundamentals, for which they claim there is little use in industry. Fortunately, however, this attitude is off-set by the opinion of more far-seeing employers that the universities are supplying graduates well able to apply their education to the solution of problems in science and technology. Dr. Beaven concluded by referring to postgraduate training and agreed with Dr. Powell that part-time or summerstudy courses would be invaluable, and especially the postgraduate courses proposed by Prof. P. M. S. Blackett (Bull. Inst. Phys., 8 (3), 86; 1957).

The point of view of the university teacher was put by Mr. W. R. S. Garton (Imperial College, London), who supported and amplified comments by Dr. Beaven on the necessity for concentration on fundamentals in academic training. Spectroscopists engaged, for example, in analytical work, recognize the importance of this when considering prospects of the extension of methods, particularly in the field of electrical discharge phenomena. In a good degree course in physics a man who ultimately took up analytical work would automatically become well versed in these respects. With regard to Dr. Powell's remarks he thought it was interesting that at the Imperial College, the second-year physics students supplement a course of twelve lectures in atomic spectra by a laboratory course of some twenty-four hours work in which, apart from photography and analysis of a number of series spectra, they obtain manipulative experience by setting up and adjusting a spectrograph and by measuring high-resolution plates, etc.

Mr. A. S. Nickelson (U.K. Atomic Energy Authority, Research Group), while agreeing with most of the opinions expressed by previous speakers on the training of graduates, felt that some serious consideration should be given to the training of nongraduate assistants - "the men and girls who do all the work" - for, ultimately, the success of a spectroscopic unit was a measure of the quality of the personnel and of the leadership given to them. Their usefulness and eventual progress must depend on a wise scheme of training by the senior staff, as very few new entrants could be expected to have any real practical knowledge of the subject. Mr. Nickelson confirmed Dr. Powell's experiences in interviewing applicants for posts and found that most entrants at Advanced level standard have only the haziest ideas of analytical chemistry and none whatever of spectroscopy. Preliminary training could be obtained in some technical colleges, but this would only touch on the fringe of the subject. He considered that much good could be done by senior spectroseopists giving lectures to sixth forms and thus inspiring some interest at the grammar-school level. He himself had done this and was in no doubt as to the enthusiasm of the response.

The subject was then opened to general discussion. Mr. M. Milbourm (Imperial Chemical Industries, Ltd.), in a written communication, deplored the ignorance of many experimental spectroscopists on simple fundamental ideas, for example, the basis of the optical density scale and the reason why emission spectra appear as lines. He thought that 
while first consideration in the training of spectroscopists should be given to fundamentals he strongly deprecated any formal course of instruction which set out to train people to be spactroscopists only. Their education must be such as to give them a measure of flexibility consistent with their own capabilities.

Mr. G. F. Lothian (University of Exeter) considered that it was important that the new graduate should have acquired a broad and sound knowledge of fundamentals with some grounding in experimental methods and could not be expected to know much spectroscopy at this stage. Practical experience in the handling of instruments could be obtained with relatively simple apparatus.

A constructive note was introduced by Mr. E. H. S. van Someren (Murex Welding Processes, Ltd.), who read to the meeting a paper issued by the Groupement pour l'Avancement des Méthodes Spectrographiques (G.A.M.S.), which included an appreciation of the situation regarding the training of spectroscopists in France and details of a training scheme which had proved popular and successful. (This will be published in Spectrochimica Acta.)

Prof. W. C. Price (King's College, London), referring to Dr. Powell's observations, considered that lack of knowledge of spectroscopic techniques among graduates largely arose from the fact that, in the past, few lecturers have had direct experience of these methods. This situation could be expected to change in the future since the rapid growth of ultraviolet and infra-red techniques in academic and research laboratories made possible by the availability of good reliable commercial instruments has meant that a high proportion of teaching staff use them in their own researches, and the experience thus gained would tend to be passed on to students. $\mathrm{He}$ disagreed, therefore, with Mr. Lothian and considered that the task of bringing the student into close familiarity with many physical phenomena having fundamental significance (and therefore of grest educational value) could often be done only with relatively complex and expensive equipment.

Miss J. M. Rooke (Metropolitan-Vickers, Ltd.), on the question of the training of non-graduate assistants, suggested that a national diploma in spectroscopy, or some similar qualification, should be instituted so that such staff could, by taking a recognized course of training, obtain tangible proof of their knowledge of the subject. This suggestion led to some discussion as to the availability of suitable training courses, and Dr. N. Pentland (vice-chairman, Education Group), of Brighton Technical College, directed attention to the diploma courses in applied physics now being run by some of the major technical colleges. At Brighton the full-time and the sandwich course both include spectroscopy. He recommended the higher national certificate course for more junior workers, as this often included spectroscopy, although generally the content of such courses is dependent on the requirements of local industry.

Mr. K. M. Bills (Mond Nickel Co., Ltd.) suggested that the essential pre-requisite to securing an improvement in the standard of education of spectroscopists was to convince potential workers in this field (and their teachers) that the profession is worthy of their attention, and this was a task for the spectroscopist himself. This would have the effect of improving the standard of workers entering the field.

Mr. F. W. J. Garton (U.K. Atomic Energy Authority, Research Group) appealed for a practical outcome for the afternoon's discussion. He suggested. that the committees of the two Groups might meet to consider the question further, including a survey of current training courses and those which have been held in recent years, and if possible to formulate a scheme for training which might lead to a suitable qualification as suggested by Miss Rooke. This idea was generally accepted by the meeting and the first meeting of the two committees was arranged to be held on April 10.

F. W. J. Garton

\section{ELECTRON MICROSCOPY IN ASIA AND OCEANIA}

7 HE first Regional Conference on Electron Microscopy in Asia and Oceania was held in Tokyo, Japan, during October 23-27. It was organized under the auspices of the International Federation of Electron Microscope Societies, and was one of a series of regional conferences in electron microscopy planned by the International Federation at the time of the International Conference on Electron Microscopy in London in July 1954. The Tokyo Conference was arranged by the Society of Electron-Microscopy, Japan, with support of the Science Council of Japan and the Ministry of Education.

The Conference was attended by more than a hundred Japanese scientists, and by electron microscopists from the following countries in Asia and Oceania : India, Indonesia, Cambodia, Republic of China (Formosa), and Peoples Republic of China. Several countries outside the Asian and Oceanic area were also represented. There were six scientists from the Soviet Union, five from the United States, and two from Germany, including Prof. Ernst Ruska of the Fritz-Haber Institute of the Max-Planck-Gesellschaft, Berlin-Dahlem. Prof. Ruska took a leading part in the Conference, officially representing the International Federation of Electron Microscope Societies as its president. The Conference met under the shadow of the recent sudden death of Prof. von Borries, whose life and contributions were commemorated by a moving eulogy presented by his pupil, friend and collaborator, Prof. Ruska. Prof. Ruska also addressed the Conference on the history of the development of electron microscopes, on the influence of heating and cooling the specimen in an electron beam with respect to contamination of the specimen, on new trends in design of electron microscopes, on resolution, and on effects of crystalline specimens on an electron beam.

Fifty-six papers were presented. Since it is not appropriate to summarize all, an effort will be made to present impressions relating to the status of electron microscopy in some of the countries represented.

It was evident that electron microscopy in Japan is very vigorous indeed. There are more than 330 electron microscopes in Japan, most of them of Japanese manufacture. There are four companies engaged in the design and commercial manufacture of electron microscopes in Japan, and an active export of their instruments is developing. Two Japanese permanent magnet microscopes are on the market, for which resolutions of better than $25 \mathrm{~A}$. are claimed. Two Japanese manufacturers offer electromagnetic microscopes said to be capable of a resolution of 10 A. One company has developed a $300 \mathrm{kV}$. 